\title{
The influence of chronic supply of vanadium compounds on organ weights and body mass in animal diabetes model (NZO)
}

\author{
Mirosław Krośniak ${ }^{a, k}$, Janusz Szklarzewicz ${ }^{b}$, Ryszard Grybośb, Barbara Tatara, Metin Yildirimº, Bilge Sahin ${ }^{c}$ \\ Nafize Didem Yuksek ${ }^{c}$ Mustafa Ustundag ${ }^{\circ}$ \\ ${ }^{a}$ Department of Food Chemistry and Nutrition, Medical College, Jagiellonian University, 30-688 Kraków, Medyczna 9 \\ ${ }^{\mathrm{b}}$ Faculty of Chemistry, Jagiellonian University, 30-387 Kraków, Gronostajowa 2 \\ ' Students from ERASMUS program from Mersin University (Turkey) during stage at Faculty of Pharmacy, Medical College, \\ Jagiellonian University
}

\section{Article history:}

Received 3 March 2019

Received in revised form

19 March 2019

Accepted 3 April 2019

Available online 4 April 2019

\begin{abstract}
Vanadium is an element that has an effect on improving glucose levels in animals with diabetes. However, its operation is strongly dependent on the chemical structure of compounds of this element. The influence of newly synthesized vanadium compounds on biochemical processes is also unknown. The paper presents the influence of eight new vanadium compounds on organ weights of animals (mice NZO) in whom diabetes was induced by a high-fat diet during 8 weeks. Tested vanadium complexes were administered by 5 weeks. After this time organs were collected and weighed. Tested complexes had a remarkable different effect on organ weights, despite having similar composition ([VO(L)(phen)] and the same co-ligand (1,10-phenanthroline). This indicate on separate metabolic pathways of these compounds in the body of tested animals and role of the tridentate L Schiff base ligands. The compounds C2, C3 and C5 shoved biggest influence on organs weight and these results suggest influence on the metabolic pathways and therefore are interesting for further investigations.
\end{abstract}

Keywords: vanadium, organ weight, body mass, diabetes

\section{Introduction}

Vanadium is one of the essential human bio-elements. It was discovered in 1801 by the Spanish chemists Andrés Manuel del Rion. This discovery, however, has not been recognized by the world of science and was rediscovered by Nils Gabriel Sefstrôm, a Swedish chemist, in 1831 [1]. At the beginning, his biological role was unknown. At the turn of the 19th and 20th centuries, its positive effect on the improvement of glycaemia in humans was found. These works, however, were controversial because vanadium compounds on prisoners were tested. In addition, insulin was discovered during this period, which coped better with glycemic control in people with diabetes [2,3]. The influence of vanadium compounds on living organisms up to the 1980s was studied only in the toxicological aspect [4-6]. A number of toxic effects have been demonstrated in people exposed to vanadium at work [7, 8]. The interest in vanadium as an element necessary for living organisms took place only in the 1980s. Then it was again presented its glycemic normalization activity. Since then, growing interest in vanadium compounds in biological terms has been observed. At present, its positive effect on glucose regulation [2, 3, 9-12], serum lipid lowering [13, 14], antioxidant activity in diabetes [15], anticancer activity [16-18], in goat reproduction processes [19], in bone growth processes and collagen synthesis [20], replacement of phosphates in processes using ATP [21] and in a number of others. During the research on this element, however, it was found that there are differences in its activity depending on the compound used. In bioavailability studies, it has been shown that organic compounds of this element are absorbed better than inorganic compounds [22]. In the case of the antidiabetic aspect, inorganic compounds were studied at the beginning, McNill's showed however that BMOV $(\mathrm{BMOV}=$ bisomaltolatooxidovanadium(IV)] - organic compound of vanadium worked much better than inorganic compounds [23-26]. In addition, the BMOV compound has become soon a standard of antidiabetic properties for other organic vanadium compound. Since then, a number of organic vanadium compounds have been tested in various biological aspects. Each time, researchers wanted to get the most beneficial effects with the smallest side effects that were observed at high doses of vanadium. During these works, biochemical effects were described without paying attention to the weight of organs. Our research shows how the supply of vanadium compounds affects the weight of individual organs. Changes in these weights within individual groups may indirectly inform about potential biochemical processes related to particular specific organs.

\footnotetext{
*Corresponding author: mfkrosni@cyf-kr.edu.pl
} 


\section{Materials and methods}

\section{Vanadium complexes}

Complexes $\mathrm{C} 1$ to $\mathrm{C} 8$ were synthesized by chemists from Faculty of Chemistry on Jagiellonian University as described in patent P.401493. Purity of this complexes were confirmed by elemental analysis, IR and UV-VIS spectra as well as by magnetic susceptibility measurements. For several complexes the X-ray crystal structure on single crystals were determined. As standards the following compound were used: inorganic vanadium salt R1 - $\mathrm{VOSO}_{4}$ and BMOV [bismaltolatooxidovanadium(IV)]. For described in paper vanadium complexes, $\mathrm{C} 1-\mathrm{C} 8$, chemical formulas, ligand compositions, oxidation states of vanadium and molecular weights are presented in Table 1.

Table 1.

\begin{tabular}{|c|c|c|c|c|}
\hline Symbol & Chemical structure & Formula (name) & Molar mass & $\mathrm{V}$ \\
\hline R1 & $\mathrm{VOSO}_{4}$ & Vanadyl sulfate & 163.0 & 4 \\
\hline $\mathrm{R} 2$ & {$\left[\mathrm{VO}(\mathrm{mal})_{2}\right]$} & Bis(3-hydroxy-2-methyl-4H-pyran-4-onato-O3,O4)oxo-vanadium(IV) & 316.99 & 4 \\
\hline $\mathrm{C} 2$ & {$[\mathrm{VO}(\mathrm{L})(\mathrm{phen})]$} & $\begin{array}{l}\{\mathrm{N}-(\mathrm{E})[-(5-\text { bromo-2-oxophenyl)methylidene]-4-chlorobenzene-1-carbohydra- } \\
\text { zonate) }\}(1,10 \text {-phenanthroline)oxidovanadium(IV) }\end{array}$ & 598.7 & 4 \\
\hline $\mathrm{C} 3$ & {$[\mathrm{VO}(\mathrm{L})(\mathrm{phen})] \cdot 0.5 \mathrm{H}_{2} \mathrm{O}$} & $\begin{array}{l}\text { (4-bromo-2-\{(E)-[2-(4-tetr-buthylbenzoyl)hydrazinylidene]methyl }\} \text { phenolate) } \\
\text { (1,10-phenanthroline)oxidovanadium }(\mathrm{IV}) \cdot 0.5 \mathrm{H}_{2} \mathrm{O}\end{array}$ & 629.4 & 4 \\
\hline $\mathrm{C} 4$ & {$[\mathrm{VO}(\mathrm{L})(\mathrm{phen})]$} & $\begin{array}{l}\text { (2,4-dibromo-3-methoxy-6-\{(E)-[2-(phenylacetyl)hydrazinylidene]methyl }\} \\
\text { phenolate)(1,10-phenanthroline)oxidovanadium(IV) }\end{array}$ & 687.2 & 4 \\
\hline $\mathrm{C} 5$ & {$[\mathrm{VO}(\mathrm{L})(\mathrm{phen})] \cdot 2 \mathrm{H}_{2} \mathrm{O}$} & $\begin{array}{l}\text { (4-bromo-2-\{(E)-[2-(4-hydroxybenzoyl)hydrazinylidene]methyl }\} \text { phenolate) } \\
\left(1,10 \text {-phenanthroline)oxidovanadium }(\mathrm{IV}) \cdot 2 \mathrm{H}_{2} \mathrm{O}\right.\end{array}$ & 616.3 & 4 \\
\hline C6 & {$[\mathrm{VO}(\mathrm{L})($ phen $)] \cdot \mathrm{H}_{2} \mathrm{O}$} & $\begin{array}{l}\text { (2,4-dichloro-6- }\{(\mathrm{E})-[2-(4 \text {-hydroxybenzoyl)hydrazinylidene]methyl }\} \text { phenolate }) \\
\left(1,10 \text {-phenanthroline)oxidovanadium }(\mathrm{IV}) \cdot \mathrm{H}_{2} \mathrm{O}\right.\end{array}$ & 588.3 & 4 \\
\hline C7 & [VO(L)(phen)] & $\begin{array}{l}\text { (2,4-dichloro-6- }\{(\mathrm{E})-[2 \text {-(phenylacetyl)hydrazinylidene]methyl }\} \text { phenolate })( \\
1,10 \text {-phenanthroline)oxidovanadium(IV) }\end{array}$ & 568.3 & 4 \\
\hline $\mathrm{C} 8$ & $\mathrm{~K}[\mathrm{VO}(\mathrm{L})($ phen $)] \cdot 4 \mathrm{H}_{2} \mathrm{O}$ & $\begin{array}{l}\text { Potassium (2-\{(E)-[2-(4-methoxybenzoyl)hydrazinylidene]methyl }\} \text {-4-sulfophe- } \\
\text { nolate })\left(1,10 \text {-phenanthroline)oxidovanadium }(\mathrm{IV}) \cdot 4 \mathrm{H}_{2} \mathrm{O}\right.\end{array}$ & 705.6 & 4 \\
\hline
\end{tabular}

\section{In Vivo test}

\section{Diet}

The animals received two different diets. The first was the standard diet for laboratory animals. The other was a high-fat one consisting of $15 \%$ of saturated fats and $1.5 \%$ of cholesterol.

\section{Animals}

New Zealand Obese mice $(n=264)$ in age of 5 weeks were divided into 22 groups of 12 animals (six per cage). Two, from 22 groups, were as diabetes and healthy control: other 20 groups were treated with vanadium compounds. In this groups two reference vanadium compounds: - inorganic $\mathrm{VOSO}_{4}$ and organic BMOV were used. The remaining 18 groups received vanadium complexes C1-C8. Diabetes was induced by special food containing cholesterol (1,5\%) and saturated fatty acids (15\%) by period of 8 weeks. After this time, by following 5 weeks, tested compounds were administered once per day by gavage in dose of $0,063 \mathrm{mmol} / \mathrm{kg}$ of animal body mass. In the end of experiment the animals were sacrificed using thiopentone $(60 \mathrm{mg} /$ $\mathrm{kg}$ ) and the organs were isolated and weighed on an analytical balance (Sartorius ${ }^{\mathrm{R}}$ ). 


\section{Results}

Below are presented graphics as results of experience observation. These presentation will significantly facilitate understanding of observed changes in particular groups of animals. The observed changes are discussed under each graphic.

\section{A) Brain}
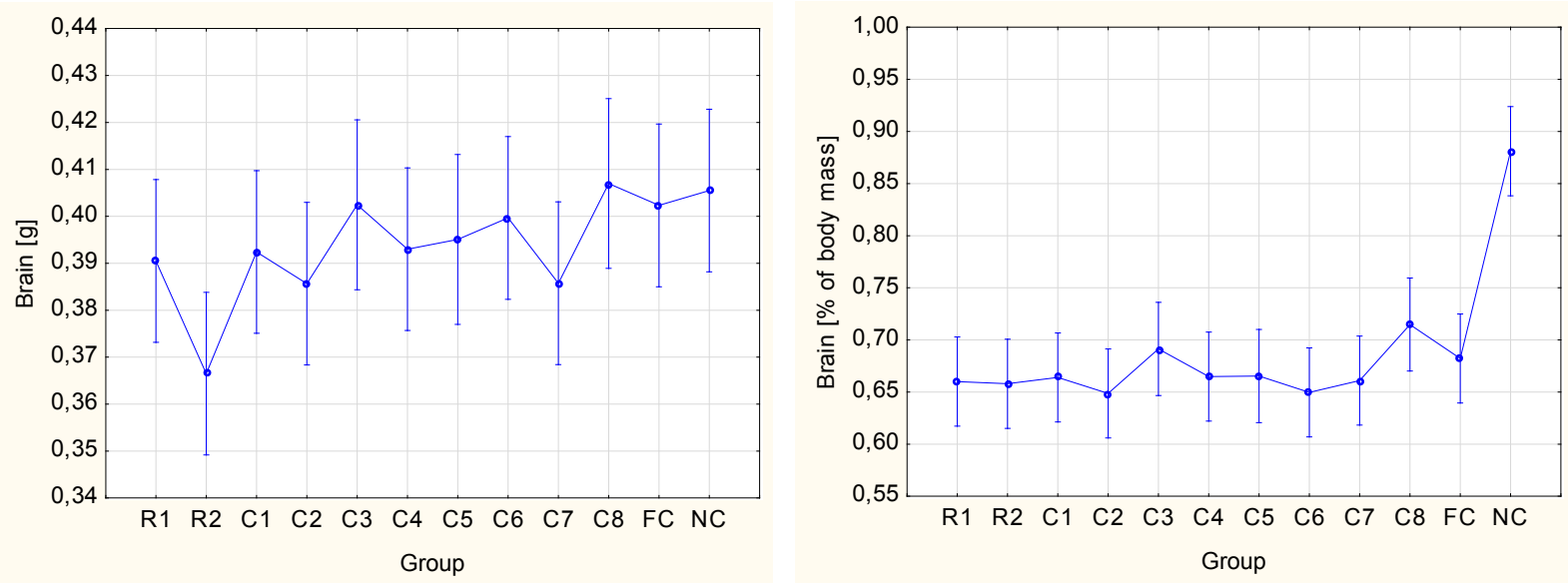

a)

b)

a) No statistical differences between groups $(\mathrm{p}>0.05)$.

b) In the case of mice that received a non-diabetic diet, the weight gain was smaller and for this reason the weight of the brain was statistically significantly higher $(\mathrm{p}>0.001)$ than the total body weight. The weight of the brain does not increase with increasing body weight.

\section{B) Lungs}
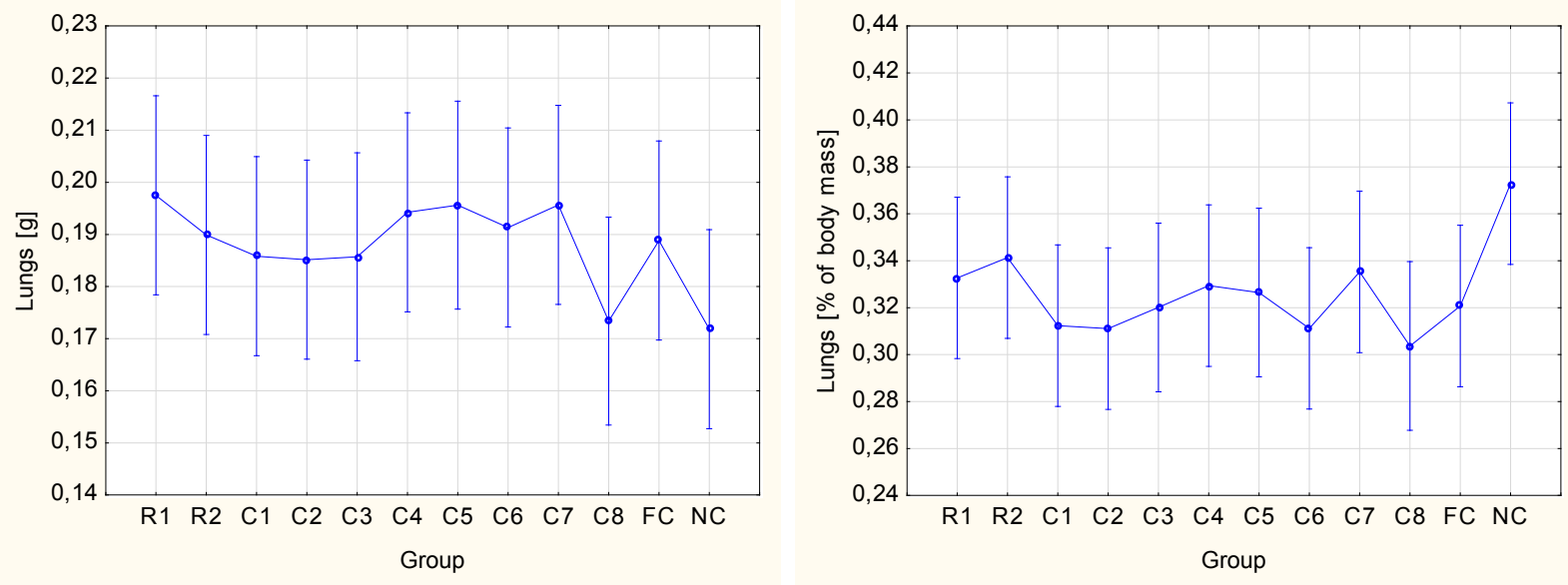

a)

b)

a) and b) There are no statistically significant differences in both cases ( $>0.05)$. The weight of the lungs increases with the weight of the body. 


\section{C) Liver}

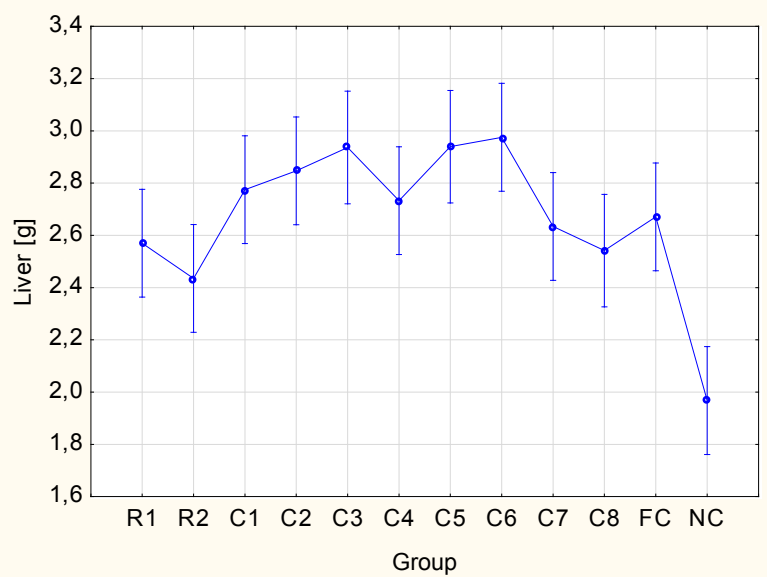

a)

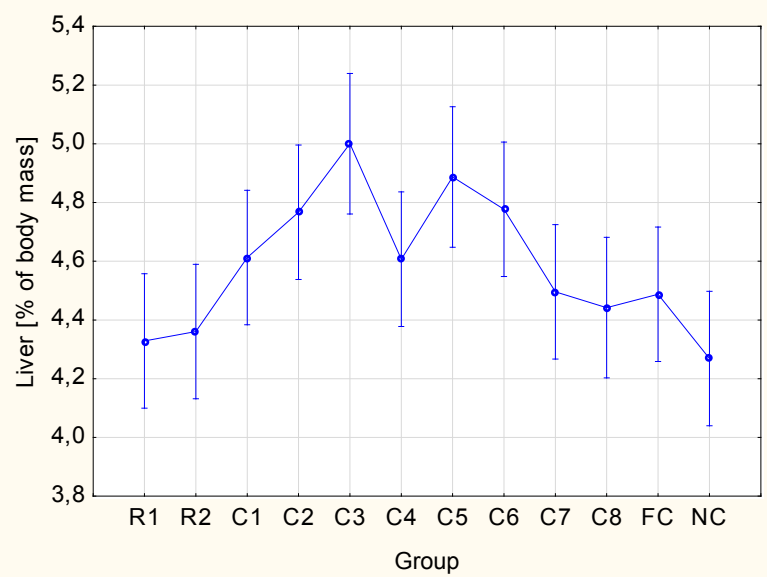

b) caused a statistically smaller increase in liver mass in relation to $\mathrm{C} 5$ compounds $(\mathrm{p}=0.049)$ i $\mathrm{C} 6(\mathrm{p}=0.013)$.

b) The percentage of liver in mice that received compound $\mathrm{C} 3$ was highest relative to all groups of animals, however, the differences were statistically significant only between the groups $\mathrm{R} 1(\mathrm{p}=0.005)$ and $\mathrm{R} 2(\mathrm{p}=0.010)$ relative to Compound $\mathrm{C} 3$. The $\mathrm{C} 3$ and $\mathrm{C} 5$ groups had a statistically significantly higher $\%$ of the liver in the body of the whole animal also in relation to the control group $(p=0.001$ and $p=0.015$ respectively).

\section{D) Heart}
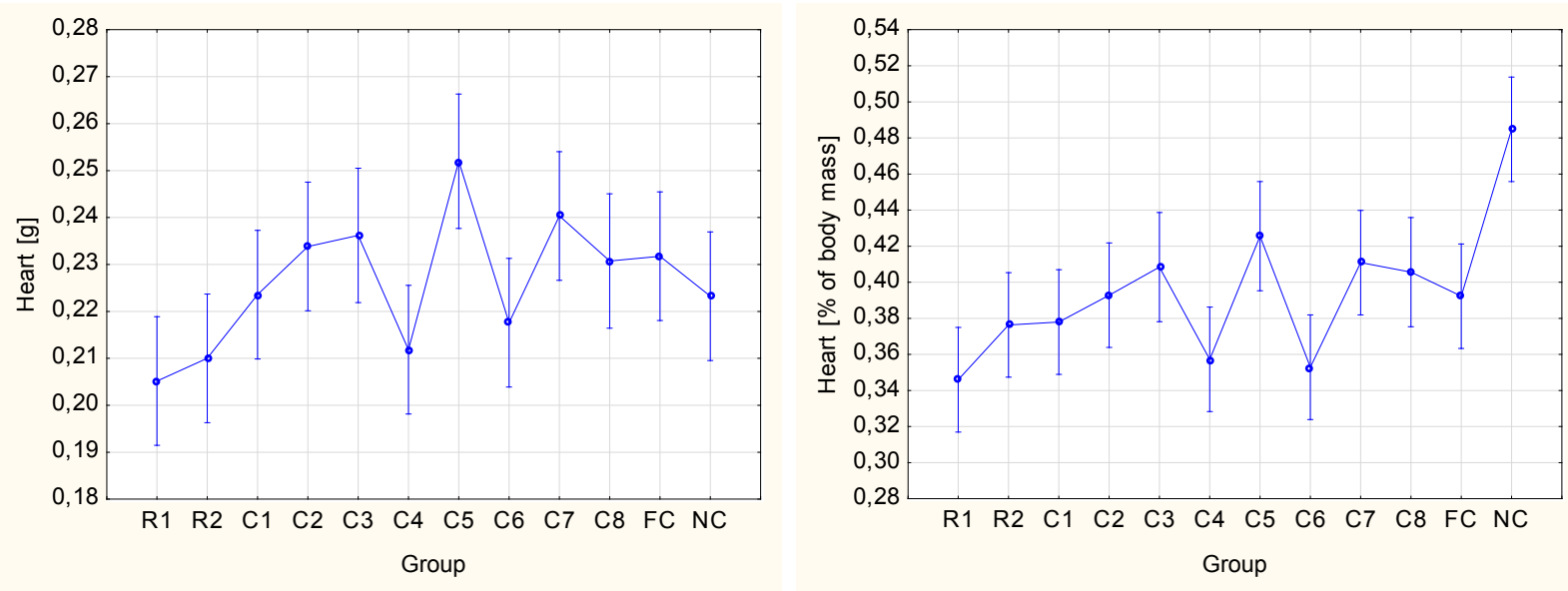

a)

b)

a) The weight of the heart was the highest in $\mathrm{C} 5$ animals compared to other groups. The differences were statistically significant between the C6 group and the R1, R2, C4, C6 groups ( $<<0.001, p=0.002, p=0.005, p=0.037$, respectively, also complex C7 statistically increased the cardiac mass relative to the $\mathrm{R} 1$ group $(\mathrm{p}=0.017)$.

b) Percentage of the heart in the mass of the whole animal was statistically the highest in the control group healthy in relation to all other groups. In the case of the C5 group a statistically significant increase in the percentage of the heart in relation to the groups R1 and C6 was observed ( $p=0.012$ and $p=0.037$ respectively). 


\section{E) Spleen}
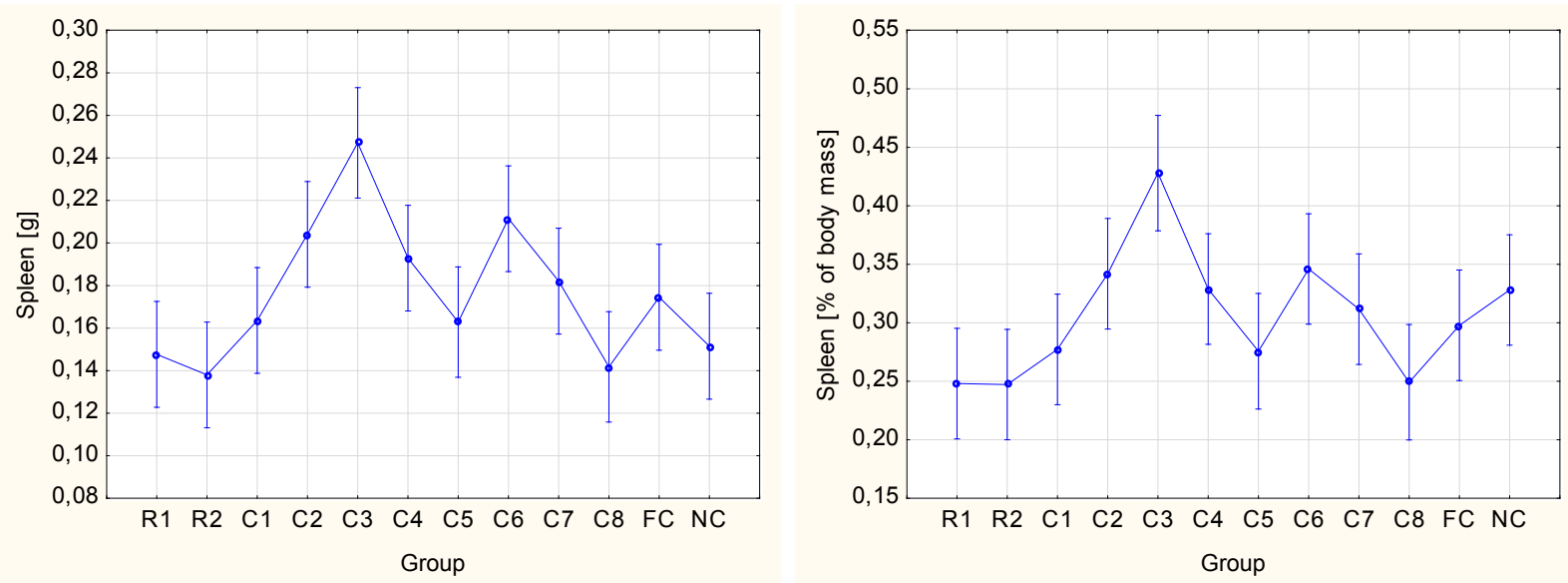

a)

b)

a) The use of vanadium compounds affected the weight of the spleen. The highest spleen weight was in the $\mathrm{C} 3$ group. The differences between the $\mathrm{C} 3$ group and the R1, R2, C1, C5, C7, C6, FC and NC groups were statistically significant ( $<<0.001, \mathrm{p}<0.001, \mathrm{p}<0.001, \mathrm{p}=0.003$, $0.023, \mathrm{p}<0.001, \mathrm{p}=0.005 ; \mathrm{p}<0.001$ respectively).

b) Taking into account the percentage of weight of the spleen of the animal observations were similar to those in the case of spleen weight.

\section{F) Pancreas}

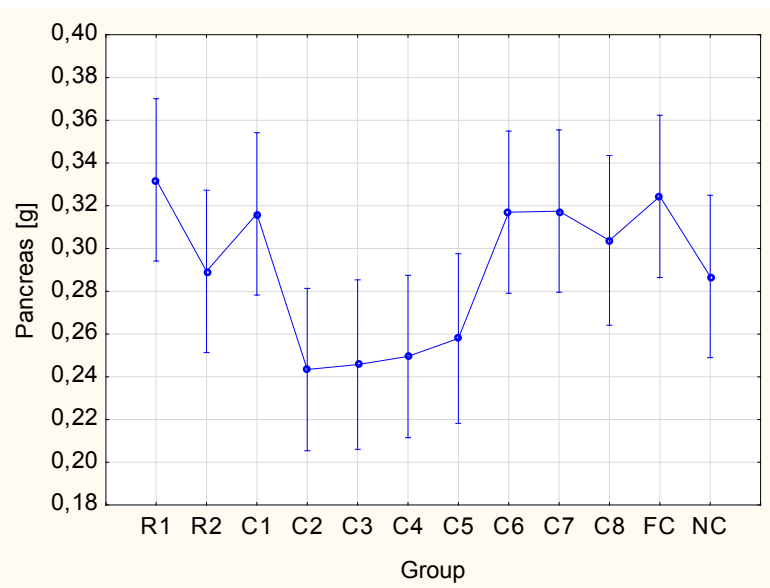

a)

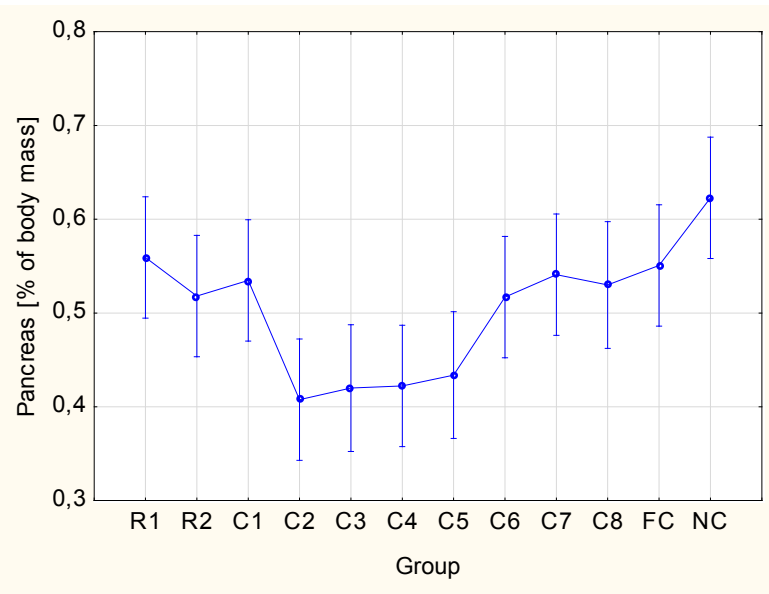

b)

a) In the group of animals with $\mathrm{C} 2$ compounds; $\mathrm{C} 3 ; \mathrm{C} 4$ and $\mathrm{C} 5$ showed a lower pancreatic mass than in the other groups. Statistically significant differences were observed between R1 and $\mathrm{C} 2$ groups $(\mathrm{p}=0.049)$.

b) Taking into account the percentage of pancreas in the body mass, the highest value was observed in animals in the control group. This value was statistically significant between the NC group and the groups: $\mathrm{C} 2$; $\mathrm{C} 3$; $\mathrm{C} 4$ and $\mathrm{C} 5$ ( $\mathrm{p}<0.001, \mathrm{p}=0.002, \mathrm{p}<0.001$ and $\mathrm{p} 0.005$ respective1y). In addition, a statistically significant difference was observed between the R1 and $C 2$ groups ( $p=0.048)$. 


\section{G) Left Kidney}

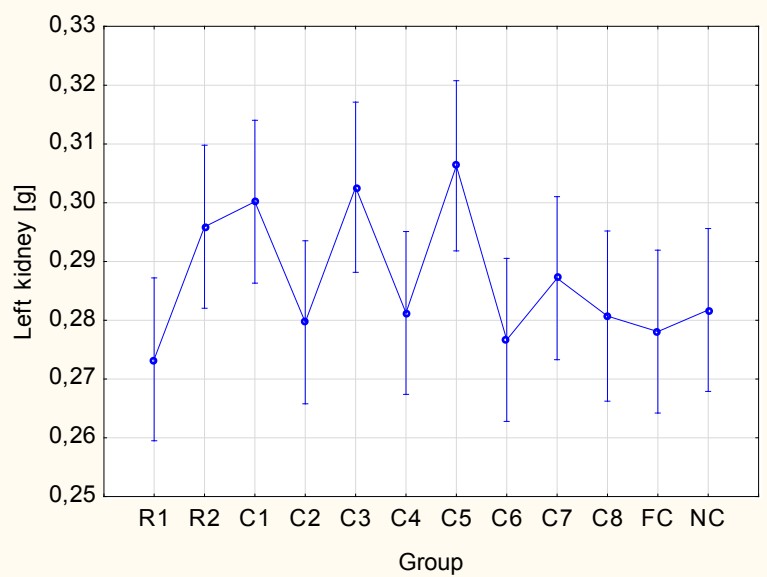

a)

a) There were no statistical differences between the groups, suggesting no effect of obesity and vanadium compounds on the mass of this organ b) In animals from the control group, a statistically significant increase in the percentage of kidney weight was observed compared to that of the animal body.

\section{H) Right kidney}
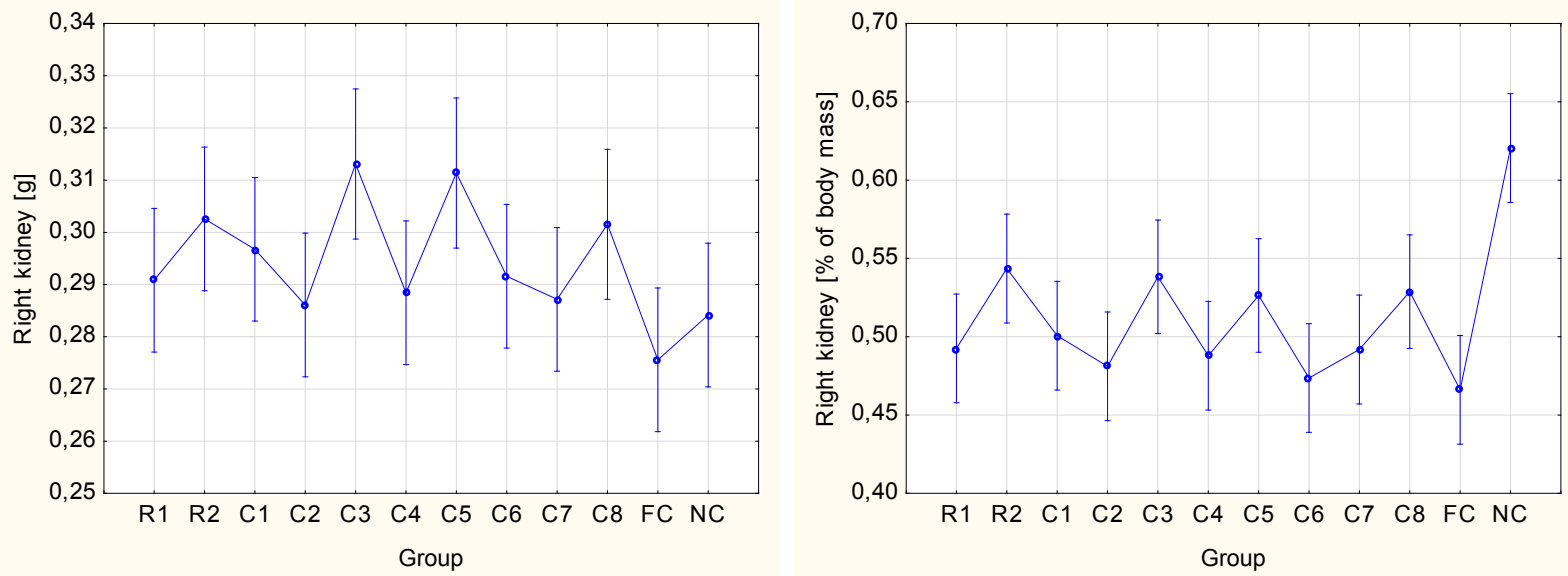

a)

In the case of the right kidney, the situation was identical to that in the left kidney, both for the body weight and the percentage weight in the whole body.

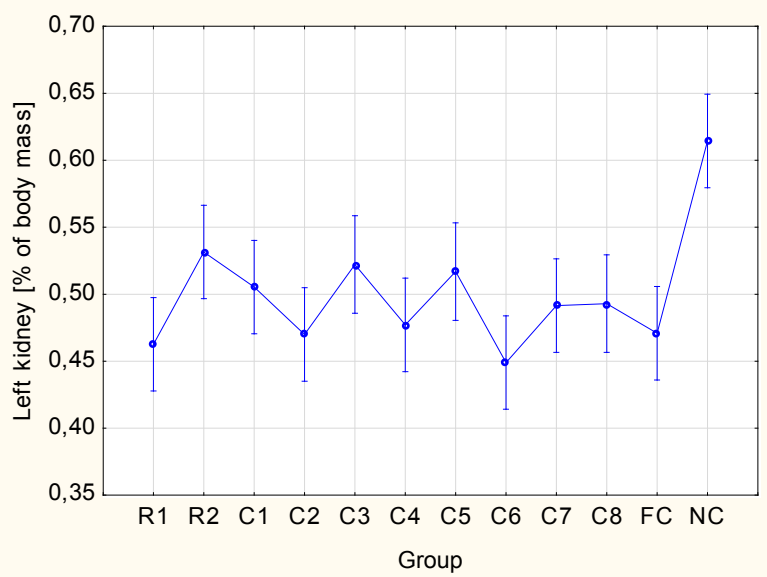

b) 


\section{I) Left testicle}
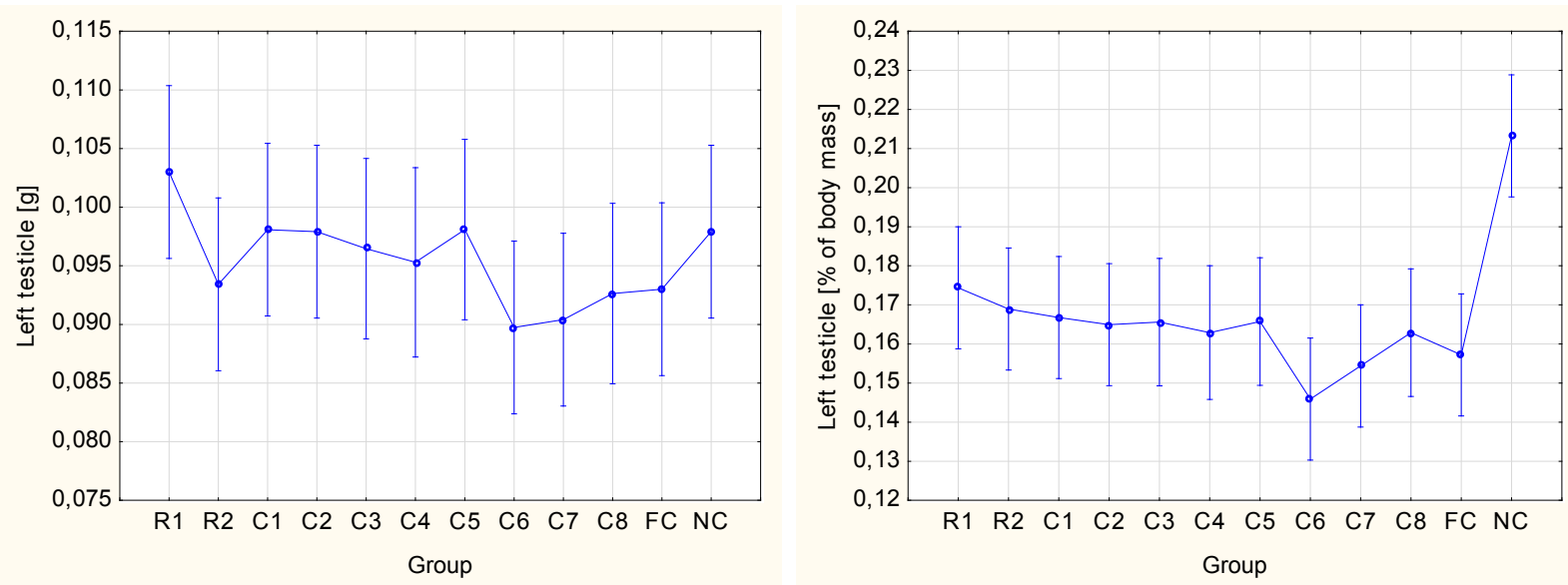

a)

b)

a) No statistical differences between groups.

b) In the control group, the percentage of testicular mass in the body mass was statistically higher than in all other groups.

\section{J) Rigt testicle}
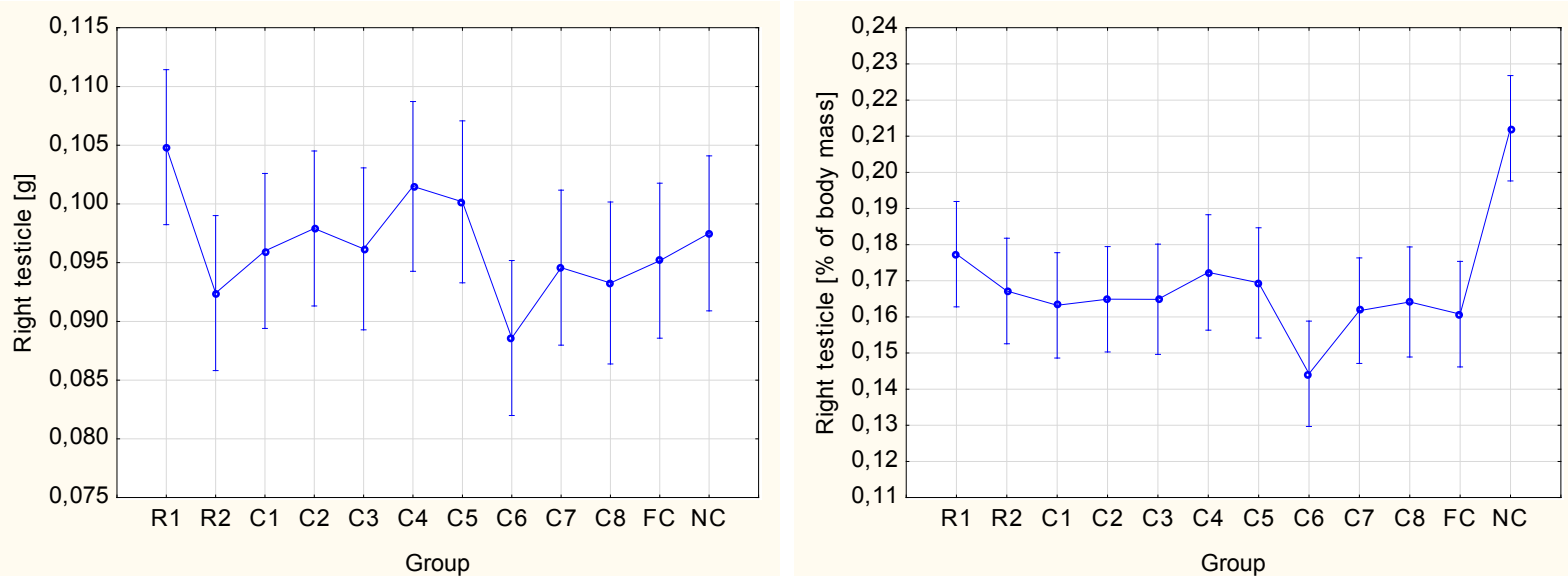

a)

b)

a) Statistically significant reduction in testes weight was observed in animals of group C6 in relation to the group with compound R1.

b) In the case of the percentage of the right core mass in the whole body mass, a statistically higher percentage was observed in control animals in relation to the remaining groups. In addition, statistically significant differences between R1 and C6 were similarly observed $(p=0.048)$. 


\section{K) Femur}

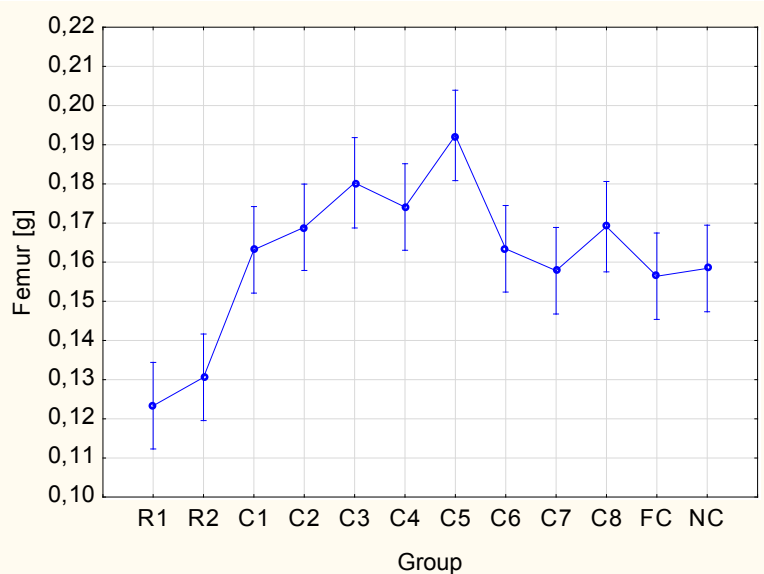

a)

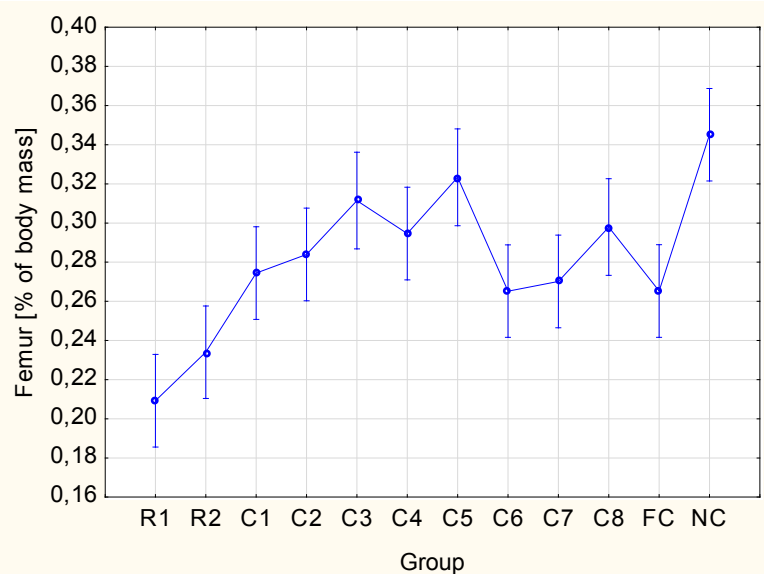

b)

a) The femoral mass varied between groups. The lowest value was observed in the R1 group and the highest in the C6 group. The differences were statistically significant between the R1 group and the $\mathrm{C} 1-\mathrm{C} 8$ groups; FC and NC. There were also statistically significant differences between the $\mathrm{C} 5$ group and $\mathrm{C} 1$ groups; 6 ; $\mathrm{C} 7 ; \mathrm{Fc}$ and $\mathrm{NC}(\mathrm{p}=0.021, \mathrm{p}=0.023, \mathrm{p}=0.002, \mathrm{p}<0.001, \mathrm{p}=0.02$, respectively).

b) Taking into account the percentage of femoral mass in the whole body mass, an identical relationship was observed within the groups with the diabetic-inducing diet. In the case of the NC Group, the highest proportion of femur in the mass of the whole body was observed statistically significantly in relation to the remaining groups, excluding $\mathrm{C} 3$ groups; $\mathrm{C} 4$; $\mathrm{C} 5$ and $\mathrm{C} 8$.

\section{L) Body mass and body mass growth}

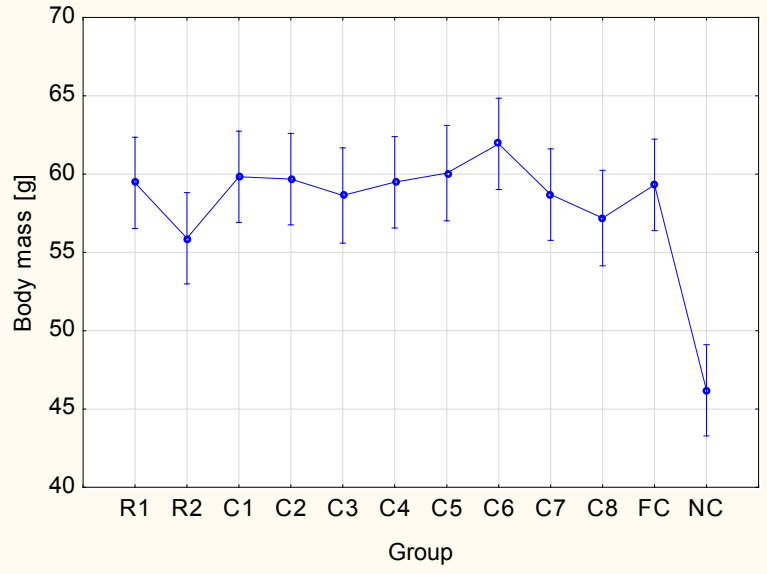

a)

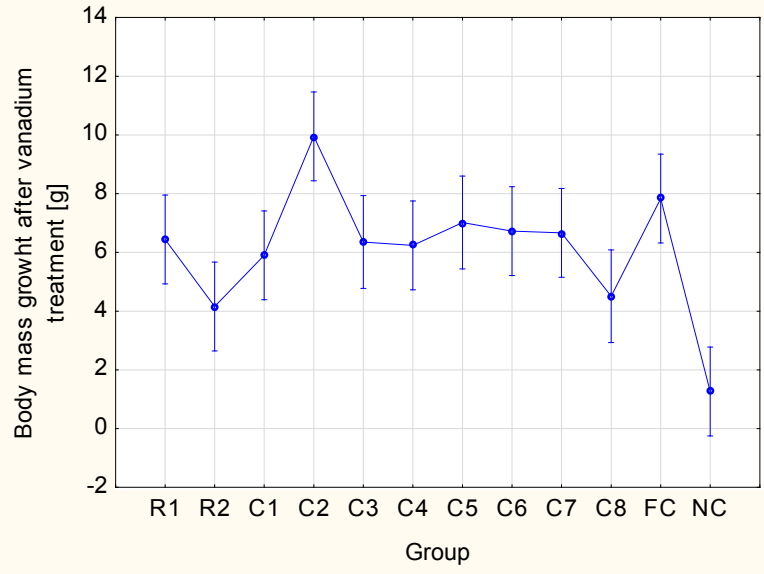

b)

a) The body weights of animals fed a diabetic diet were in each case statistically higher than the mass of animals from the NC group.

b) Taking into account the weight gain, it was observed that the $\mathrm{C} 2$ animals were the highest and the lowest in the NC group. Statistically significant differences were observed between the NC group and R1 groups; C1 - C7 and FC. Within animals with a diabetic diet, statistically significant differences were observed between the $\mathrm{C} 2$ group and the $\mathrm{R} 2$ groups; $\mathrm{C} 1 ; \mathrm{C} 4$ and $\mathrm{C} 8(\mathrm{p}<0.001, \mathrm{p}=0.010, \mathrm{p}=0.030, \mathrm{p}<0.001)$.

\section{Discussion}

Mass of organs can be quickly technique of investigation of new compounds. If organ masses will be different its suggest influence on different metabolic pathway. Many metabolic dysfunctions affect the organs structure, color or weight. Changes in the weight of organs may indicate that they are largely sensitive to the tested compounds. In addition, it can indirectly indicate which metabolic functions undergo disruption, under the influ- ence of the tested compounds, and in this way indicate possible directions for future biochemical investigations.

Type 2 diabetes is most often associated with an increase in body weight. The experiment, presented in this paper, also indicated that the diabetic diet significantly increases the body weight of animals. The administration of vanadium compounds did not statistically affect the final weight of diabetic animals caused by diet. It can be observed however, that the compounds R2 and $\mathrm{C} 8$ but not significantly reduced the weight of animals. These 
observations confirm the data from other works that in some cases a reduction in the final weight of animals, in the groups that receive vanadium compounds, is observed [12, 28, 29]. An interesting comparison was the recorded gain weight of animals from the start of vanadium administration to the end of the experiment. The reference compound and the $\mathrm{C} 8$ compound were the most responsible for weight decrease in the group of diabetic animals induced by diet. In the case of compound C2, a statistically significant increase in body mass was observed in relation to the rest of the tested vanadium compounds.

The weight of organs such as the brain, lungs and testes did not differ significantly between the groups and it cannot be said that the tested compounds had an observable effect on them. It can be noted, however, that the percentage of brain and testes was higher in animals from the control group, due to decrease of body weight. Such a result shows that regardless of body weight and mainly body fat, these organs do not change the weight in group of a similar age animals.

A very pronounced effect of the diet is observed in the case of liver mass. All animals with diabetic triggered by diet had a significantly higher liver weight compared to the healthy control group. The graph of liver weight and body weight of animals is very similar. One can also observe the effect of particular vanadium compounds on liver mass. The C3, C5 and C6 compounds caused the largest increase in the mass of this organ while compounds R2 and C8 the smallest. An interesting is the graph showing the percentage of liver weight in the total animal weight. It can be seen from this graph that compounds $\mathrm{C} 2, \mathrm{C} 3$, C5 and C6 increase the percentage of liver in the weight of the whole animal. This may indirectly indicate that the structure of a particular vanadium compound is important in hepatic metabolism. The specific biochemical measurements will be necessary to answer which metabolic changes are induced and which are inhibited by the tested compounds.

All tested compounds had an influence also on the mass of the heart. The compound C5 increased the body's mass, this may indicate on circulatory problems resulting in an increase in resistance to blood flow which were compensated by hypertrophy of the left ventricle.

Spleen is the body in which the production of immunoglobulins, as well as the processing of "old" blood cells, takes place. Increasing the weight of the spleen can indirectly suggest the influence of the test compounds on hematopoietic and immune processes. The highest increase in spleen weight is observed for the compound $\mathrm{C} 3$. Unfortunately, we are not able to discuss the nature of these changes without additional biochemical tests.

The main secretory function of the pancreas is the production of insulin, which is supposed to reduce the level of glucose. In the case of diabetes type 2, an increase in insulin resistance is observed as the body weight increases. In the conducted exper- iment, a decrease in body weight of this organ is observed in groups of animals receiving compounds (C2), C3, C4 and C5. Such a change may indicate a probable increase in insulin sensitivity, which results in a lower production of insulin needed to normalize the glucose level.

The primary function of the kidney is to remove protein metabolism products and to maintain water and electrolyte balance. The observation of the kidney weight showed that after administration of $\mathrm{C} 3$ and $\mathrm{C} 5$ compounds, that the weight of this organ increases in relation to the other compounds. Most often, kidney hypertrophy is associated with an increase in blood pressure or inflammatory problems in the urinary tract. However, the nature of these changes requires further investigations.

One of the biggest changes was observed in the weight of the femur. Compound C5 caused the largest increase in femur mass. This may indicate the degree of bone mineralization. Some studies have shown that vanadium compounds are actively involved in the processes of bone formation and these observations have coverage for some of the vanadium compounds tested in this paper [20].

\section{Conclusion}

Tested in this work vanadium compounds $\mathrm{C} 1-\mathrm{C} 8$, despite having similar composition ([VO(L)(phen)] and the same co-ligand (1,10-phenanthroline) had a remarkable different effect on organ weights. This indicate on separate metabolic pathways of these compounds in the body of tested animals and role of the tridentate L Schiff base ligands

The compounds $\mathrm{C} 2-\{\mathrm{N}-(\mathrm{E})[-(5-$ bromo-2-oxophenyl) methylidene]-4-chlorobenzene-1-carbohydrazonate) $\}$ (1,10-phenanthroline)oxidovanadium(IV); C3 - (4-bromo-2-\{(E)[2-(4-tetr-buthylbenzoyl)hydrazinylidene]methyl $\}$ phenolate) (1,10-phenanthroline)oxidovanadium(IV) $0.5 \mathrm{H} 2 \mathrm{O}$ and $\mathrm{C} 5$ (4-bromo-2-\{(E)-[2-(4-hydroxybenzoyl)hydrazinylidene]methyl $\}$ phenolate)(1,10-phenanthroline)oxidovanadium(IV) $2 \mathrm{H} 2 \mathrm{O}$ have a significant influence on the organs weight, which can inform about their large impact on the metabolic pathways and therefore are interesting for further investigations. At this moment it is impossible to esplicate what decide about observed data. Future biochemical analysis can answer what decide about observed data.

\section{Acknowledgement}

This work was partly financed by the European Regional Development Fund under the Innovative Economy Program 20072013 (WND POIG.01.03.01-174/09). Authors would like to acknowledge all participants for their contribution to this grant. 


\section{References}

1. Treviño S, Díaz A, Sánchez-Lara E, Sanchez-Gaytan BL, Perez-Aguilar JM, González-Vergara E. Vanadium_in Biological Action: Chemical, Pharmacological Aspects, and Metabolic Implications in Diabetes Mellitus. Biol Trace Elem Res, 2018 doi: 10.1007/s12011-018-1540-6

2. Sakurai H. A new concept: the use of vanadium_complexes in the treatment of diabetes mellitus. Chem Rec, 2002; 2:237248.

3. Sakurai H, Katoh A, Kiss T, Jakusch T, Hattori M. Metallo-allixinate complexes with anti-diabetic and anti-metabolic syndrome activities. Metallomics, 2010; 2:670-682.

4. Roshchin IV. Toxicology of vanadium compounds, used in modern industry. Gig Sanit, 1967,32,26-32.

5. Oberg SG, Parker RD, Sharma RP. Distribution and elimination of an intratracheally administered_vanadium_compound in the rat. Toxicology, 1978; 11:315-323.

6. Heide M, Legrum W, Netter KJ, Fuhrmann GF. Vanadium_inhibits oxidative drug demethylation in vivo in mice. Toxicology, 1983; 26:63-71.

7. Vouk V. Vanadium. In: Friberg, L. et al., ed. Handbook on the toxicology of metals. Amsterdam, Elsevier-North Holland Biomedical Press, 1979, 659-674.

8. Venugopal B, Luckey, T.D. Metal toxicity in mammals. 2. Chemical toxicity of metals and metalloids. New York, Plenum Press, 1978, 220-226.

9. Adam AMA, Naglah AM, Al-Omar MA, Refat MS. Synthesis of a new insulin-mimetic anti-diabetic drug containing vitamin A and_vanadium(IV) salt: Chemico-biological characterizations. Int J Immunopathol Pharmacol, 2017: 30:272-281.

10. Domingo JL, Gómez M. Vanadium_compounds for the treatment of human_diabetes mellitus: A scientific curiosity? A review of thirty years of research. Food Chem Toxicol, 2016; 95:137-141.

11. Ahmed El-Shazly S, Ahmed MM, Ibrahim ZS, Refat MS. Synthesis, characterization, and efficacy evaluation of a new anti-diabetic vanadyl(II) thiamine hydrochloride complex in streptozotocin-induced diabetic rats. Int J Immunopathol Pharmacol, 2015; 28:227-239.

12. Krośniak M, Francik R, Kołodziejczyk K, Wojtanowska-Krośniak A, Tedeschi C, Petrone V, Gryboś R. Investigation of the influence of_vanadium_compounds treatment in NZO mice model-preliminary study. Acta Pol Pharm, 2014; 71:271-278.

13. Huang Y, Liu F, Zhang F, Liu P, Xu T, Ding W. Vanadium(IV)-chlorodipicolinate alleviates hepatic_lipid_accumulation by inducing autophagy via the LKB1/AMPK signaling pathway in vitro and in vivo. J Inorg Biochem, 2018; 183:66-76

14. Zhang Y, Zhang Q, Feng C, Ren X, Li H, He K, Wang F, Zhou D, Lan Y Influence of_vanadium_on_serum_lipid_and lipopro- tein profiles: a population-based study amongvanadium_exposed workers. Lipids Health Dis, 2014; 24,13:39.

15. Liu Y, Xu J, Guo Y, Xue Y, Wang J, Xue C. Ameliorative effect of vanadyl(IV)-ascorbate complex on high-fat high-sucrose diet-induced hyperglycemia, insulin resistance, and oxidative stress in mice. J Trace Elem Med Biol, 2015; 32:155-161.

16. Ni L, Zhao H, Tao L, Li X, Zhou Z, Sun Y, Chen C, Wei D, Liu Y, Diao G. Synthesis, in vitro cytotoxicity, and structure-activity relationships (SAR) of multidentate oxidovanadium(iv) complexes as anticancer agents. Dalton Trans, 2018; 47:10035-10045

17. Crans DC, Yang L, Haase A, Yang X. Health Benefits of Vanadium and Its Potential as an Anticancer Agent. Met Ions Life Sci, 2018, 18.

18. Patra D, Paul S, Majumder I, Sepay N, Bera S, Kundu R, Drew MGB, Ghosh T. Exploring the effect of substituent in the hydrazone ligand of a family of $\mu$-oxidodivanadium(v) hydrazone complexes on structure, DNA binding and anticancer activity. Dalton Trans, 2017; 46:16276-16293.

19. Haenlein GFW, Anke M. Mineral and trace element research in goats: A review Small Ruminant Res, 2011; 95:2-19.

20. Facchini DM, Yuen VG, Battell ML, McNeill JH, Grynpas MD. The effects of vanadium treatment on bone in diabetic and non-diabetic rats. Bone, 2006; 38:368-377.

21. Francik R, Krosniak M, Barlik M, Kudła A, Grybos R, Librowski $\mathrm{T}$ Impact of vanadium complexes treatment on the oxidative stress factors in Wistar rats Plasma. Bioinorg Chem Appl, 2011; 206316.

22. Krosniak M, Azay-Milhau J, Grybos R, Cros G, Gatacceca F, Brés J. Vanadium pharmacokinetics and bioavailability of two vanadium bipyridine complexes, with reference to vanadyl sulfate, after oral administration to streptozotocin-induced diabetic rats. Metal ions in biology and medicine Vol. 10 / Ed. Philippe Collery, Ivan Maymard, Theophile Theophanides, Lylia Khassanova, Thomas Collery. Paris: John Libbey Eurotext, 2008; 769-775.

23. Yuen VG, Orvig C, McNeill JH. Glucose-lowering effects of a new organic_vanadium_complex, bis(maltolato)oxovanadium(IV). Can J Physiol Pharmacol, 1993; 71:263-269.

24. Yuen VG, Orvig C, McNeill JH. Comparison of the glucose-lowering properties of vanadyl sulfate and bis(maltolato)oxovanadium(IV) following acute and chronic administration. Can J Physiol Pharmacol, 1995; 73:55-64.

25. McNeill JH, Yuen VG, Dai S, Orvig C. Increased potency of vanadium using organic ligands. Mol Cell Biochem, 1995; 153:175-180

26. Thompson KH, Lichter J, LeBel C, Scaife MC, McNeill JH, Orvig C. Vanadium treatment of type 2 diabetes: a view to the future. J Inorg Biochem, 2009; 103:554-558.

27. Urząd Patentowy Rzeczypospolitej Polskiej Patent 231079 $\mathrm{z}$ dnia 25.05.2018, http://regserv.uprp.pl/register/application?number $=$ P.401493 
28. Sheela A, Roopan SM, Vijayaraghavan R. New diketone based vanadium complexes as insulin mimetics. Eur J Med Chem, 2008; 43:2206-2210.

29. Phanse MA, Patil MJ, Abbulu K. Synthesis, characterization and evaluation of the suppression of insulin resistance in Type-IIdiabetes mellitus animals by treatment with metal complex. Saudi J Biol Sci, 2016; 23:420-425. 